\title{
When should a cervical collar be used to treat neck pain?
}

\author{
Stefan Muzin - Zacharia Isaac · Joseph Walker · \\ Omar El Abd · Jennifer Baima
}

Published online: 12 December 2007

(C) Humana Press 2007

\begin{abstract}
Neck pain is one of the most prevalent and costly health problems in the United States. It remains a complex, subjective experience with a variety of musculoskeletal causes. Although, cervical collars are a seemingly benign intervention, they can have adverse effects, especially when used for longer periods of time. It is feared that a long period of immobilization, can result in atrophy-related secondary damage. Many physicians cite anecdotal evidence of their clinical utility and soft cervical collars are often prescribed by convention for patients complaining of neck pain. The use of cervical collars to treat neck pain is an area of controversy. This review article examines the current evidence and studies related to recommending cervical collars for neck pain of a variety of etiologies.
\end{abstract}

Keywords Neck pain - Whiplash · Cervical collars · Immobility $\cdot$ Physical therapy $\cdot$ Exercise

\section{Introduction}

Neck pain is one of the most prevalent and costly health problems in the United States [1]. Among US residents, 50-70\% will experience neck pain at least once in their lives, as many as one-third are affected each year, and about $10 \%$ suffer from neck pain at any given time [2].

S. Muzin $(\bowtie) \cdot$ Z. Isaac · J. Walker · O. E. Abd · J. Baima Department of Physical Medicine and Rehabilitation, Harvard Medical School, Boston, MA, USA

e-mail: smuzin@partners.org

Z. Isaac · J. Baima

Brigham and Women's Ambulatory Spine Service, Chestnut Hill, MA, USA
Surveys of the general population have found that the 1year prevalence rate for neck and shoulder pain to be 16 $18 \%$ [3]. It remains a complex, subjective experience with a variety of musculoskeletal causes. Almost $85 \%$ of all neck pain results from acute or repetitive neck injuries or chronic stresses and strain [4].

Although the etiology of neck pain is usually known, it is often difficult to predict which patients will respond to conservative care and which patients will have persistent pain, despite several interventions. Most musculoskeletal conditions resulting in neck pain respond quickly to conservative treatment and heal without sequelae [5].

Automobile-associated neck disorders may be more refractory. Ten years after the onset of neck pain, the majority of patients $(79 \%)$ have improved, but less than half $(43 \%)$ are pain free, and nearly one-third (32\%) have persistent, moderate to severe pain [6]. Patients with generalized hypersensitivity to stimuli, usually suffer from greater symptoms of whiplash injuries. Also, those with higher initial levels of pain and disability after whiplash injury will have a worse outcome [7].

Table 1 discusses the ranges of motion afforded by the various cervical collars and braces [11].

Soft cervical collars are the least restrictive, allowing the closest to normal range of motion. As many as $76 \%$ of patients report reduced pain with their use [12]. Although the collar may be of symptomatic benefit, there is no evidence on long-term outcome [13]. Many physicians cite anecdotal evidence of their clinical utility and soft cervical collars are often prescribed by convention for patients complaining of neck pain.

Although, cervical collars are a seemingly benign intervention, they can have adverse effects, especially when used for longer periods of time. It is feared that a long period of immobilization, can result in atrophy-related 
Table 1 Normal cervical motion from occiput to first thoracic vertebra and the effects of cervical orthoses

\begin{tabular}{lccc}
\hline & & \multicolumn{2}{l}{$\begin{array}{l}\text { Mean of normal motion } \\
(\%)\end{array}$} \\
\cline { 3 - 4 } & $\begin{array}{l}\text { Flexion/ } \\
\text { extension }\end{array}$ & $\begin{array}{l}\text { Lateral } \\
\text { bending }\end{array}$ & Rotation \\
\hline Normal [8] & 100.0 & 100.0 & 100.0 \\
Soft collar [8] & 74.2 & 92.3 & 82.6 \\
Philadelphia collar [8] & 28.9 & 66.4 & 43.7 \\
SOMI brace [8] & 27.7 & 65.6 & 33.6 \\
Four-poster brace [8] & 20.6 & 45.9 & 27.1 \\
Yale cervicothoracic & 12.8 & 50.5 & 18.2 \\
$\quad$ brace & & & \\
Halo device [8] & 4.0 & 4.0 & 1.0 \\
Halo device [9] & 11.7 & 8.4 & 2.4 \\
Minerva body jacket & 14.0 & 15.5 & 0 \\
$\quad$ [10] & & & \\
\hline
\end{tabular}

secondary damage. Atrophy-related secondary damage after immobilization in closed plaster casts has been described in muscle, bone, capsular, and tendinous tissue. Animal experiments have shown that structural changes can be detected in healthy muscle tissue after an immobilization period of only 1 week [14]. A transfer of this knowledge to soft cervical collars is difficult, because a soft collar allows a substantial degree of movement. Also, it is doubtful whether muscular changes can be attributed to wearing a cervical collar alone or whether they may be explained by physiologic mechanisms of pain avoidance [15].

Hard collars are most commonly prescribed for cervical spine stabilization following either trauma, surgery, or fractures/dislocations. There are many documented adverse effects with hard collars including, pain, breathing restriction, tissue ischemia, difficult nursing care, increased risk of aspiration, and high costs [16]. While hard collars are an important part of acute injury and spine stabilization, they are not routinely used to manage pain.

The use of cervical collars to treat neck pain is an area of controversy. The available research in this area in general, finds limited roles for collars. Mechanism of injury, clinical symptoms, and response to bracing may vary based on diagnosis and etiology of neck pain. This review will examine the available evidence for recommending cervical collars based on the various etiologies of the neck pain.

\section{Whiplash patients}

Whiplash is currently defined as a traumatic injury to the soft tissue structures in the region of the cervical spine caused by hyperflexion, hyperextension, or rotation injury in the absence of fractures, dislocations or intervertebral disk herniations [17]. Symptoms may start immediately or be delayed. Patients with neck pain after a whiplash injury from a rear impact traffic accident commonly present to an ER or trauma center. After an osseous or neurological injury to the cervical vertebral column is excluded, the non-specific diagnosis of soft tissue sprain/strain or "whiplash" is made [18]. In clinical practice, the patient is often discharged with a soft cervical collar and analgesia for pain relief.

There are no established criteria or guidelines to help the clinician decide which patients should be prescribed a soft cervical collar and/or rest and neck immobilization. However, there have been several studies that address the efficacy of cervical collars compared with other treatments (mainly exercise and mobilization) for neck pain due to whiplash injury.

In a study published in 1986 by Mealy et al. [19], 61 patients who sustained acute cervical whiplash injuries were randomized to either standard treatment or early active mobilization. The group assigned to active treatment received neck mobilization and daily exercises of the cervical spine. The patients assigned to standard treatment were given a soft cervical collar and were advised to rest for 2 weeks before beginning gradual mobilization. Pain intensity using a linear analog scale (0-10) and cervical range of motion (flexion, extension, rotation, and lateral bending), were both measured after 4 and 8 weeks. After 8 weeks, the group treated with early mobilization, fared better in terms of pain intensity and cervical movement. The authors concluded that initial immobilization after whiplash is associated with prolonged symptoms and more rapid improvement can be achieved through increased activity.

Mckinney et al. [20] assessed the long-term (2 year) effects of early mobilization in the whiplash population. A total of 247 patients presenting within $48 \mathrm{~h}$ after having a flexion-extension neck sprain from a road accident were randomly assigned to one of the three groups; a physiotherapy program, advice on mobilization, or conservative treatment (rest and cervical collar). After 2 years, $68 \%$ of the patients responded via a mailed questionnaire. Within this population, there was no significant difference in the percentage of patients with symptoms between the group receiving rest plus collar $(46 \%)$ versus the group that received a specialized physiotherapy program (44\%). However, in the group that received advice on early mobilization, a significantly lower percentage $(23 \%)$ reported symptoms after 2 years. From this study we see that there may be psychological advantages in making patients responsible for their treatment, since the patients who received advice only fared better than the group assigned to physiotherapy. The authors concluded that 
advising whiplash patients on early mobilization results in better outcomes.

Similarly, Rosenfeld et al. [21] sought to investigate the differences in two treatment protocols (active versus standard) with regard to pain and cervical range of motion in patients who sustained a whiplash injury. A total of 97 patients were randomized to four groups; active versus standard treatment and early (within 96 h) versus delayed (after 2 weeks) treatment. The active group was instructed on a home exercise program, while the standard group was given information about the mechanism of injury, instructed to rest for the first week, and was given the option of using a soft cervical collar. Cervical range of motion and pain intensity (measured by visual analog scale), were measured after 6 months. The group randomized to exercise fared better in terms of pain intensity reduction. A 30-point reduction (scale of 100) in pain was reported in the active group treated within $96 \mathrm{~h}$. The active group which received delayed treatment (after 2 weeks) reported a 15-point reduction in pain. No differences could be seen in the improvement of cervical ROM between the active and standard treatment protocol. This study suggests that in whiplash patients, early activity is superior to rest and immobilization with regards to pain intensity.

Along these lines, a study by Borchgrevnick et al. [22] randomized patients with whiplash injury within the first 14 days to either return to their usual activities (no sick leave or cervical collar), or to have 14 days of sick leave from work and be immobilized with a soft cervical collar during that time. At 6 months, the "act-as usual" group had significantly improved outcomes with regard to subjective symptoms such as pain, stiffness, memory, and concentration.

In 1995, the Quebec task force (QTF) adopted a classification system of whiplash associated disorders (WAD) [23]. WAD grade 1 indicates neck complaints (such as pain, tenderness, and stiffness) but no physical signs, WAD grade 2 indicates neck complaints and musculoskeletal signs (i.e., decreased ROM or muscle weakness), WAD grade 3 indicates neck complaints and neurological signs, and grade 4 indicates neck complaints and fracture or dislocation.

A recent study [24] randomized 200 patients who presented to the ER within $48 \mathrm{~h}$ of a motor vehicle collision with WAD grade 1 or 2 to either immobilization with a soft cervical collar or to receive exercise with a physiotherapist. Both the groups were followed for 6 weeks and were compared in terms of VAS (visual analog scale) pain intensity and disability. The exercise group had lower VAS pain intensity and disability scores. The authors concluded that early exercise is superior to collar therapy in reducing pain and disability for whiplash injuries.
A Cochrane Database literature review [25] suggests that although there is a trend suggesting that active interventions are more effective than passive ones, no clear conclusion can be drawn. All of these studies suggest that not only are cervical collars not helpful for whiplash related neck pain and that they may even make matters worse by encouraging immobility.

Based on these studies, Logan et al. [26] concluded that the traditional use of soft collars for neck sprains and strains is no longer considered best practice. The temporary relief of pain and support given by a soft collar may prolong recovery of patients. They recommend the following protocol for management of whiplash injuries: No cervical collar, regular analgesia, early home exercise program, and physiotherapy if symptoms persist.

In contrast to the above studies, Kongsted et al. [27] randomized a total of 458 patients who had been exposed to a rear-end or frontal car collision with symptoms within $72 \mathrm{~h}$ to three different intervention groups. One group was assigned to immobilization in a semirigid Philadelphia neck collar for 2 weeks, followed by instruction by a physical therapist about active mobilization. The second group ("Act as Usual") received education about the natural course of whiplash and advice on early mobilization. The third group was assigned a 6-week course of physical therapy. Self-reported data at 1-year follow-up were used as the primary outcome measures. There were no significant differences found between the intervention groups with regard to their pain rating (scale of 1-10), disability (measured with the Copenhagen Neck Functional Disability Scale) or work ability after 1 year. Based on these results the authors concluded that earlier recommendations of active treatment regimens for whiplash patients should not be universally prescribed. These conclusions have been reproduced in other recent trials [28, 29].

The issue that remains to be decided is whether cervical collars may in fact be harmful for whiplash patients. The two studies discussed below suggest that they may not be, provided that their use is limited to 10 days.

Gennis et al. [30] focused on the role of soft cervical collars in the early management of whiplash-injury-related pain. A total of 196 patients who were in the emergency department with neck pain following an automobile accident were randomized to either a soft cervical collar or to usual care. The patients in the soft cervical collar group were instructed to wear the collar as much as they could tolerate for the first 2 weeks after injury. The other group served as the control. Both the groups were advised to rest and given analgesics at the discretion of the treating physician. At 6 weeks follow-up there was no difference in the groups in terms of pain, complete recovery, or improvement. They concluded that soft cervical collars do not influence the duration or degree of persistent pain. 
Dehner et al. [31] investigated the effects of 2 vs. 10 days of immobilization with a soft cervical collar, on pain, disability, and ROM in patients with WAD grade 2 whiplash injuries. The patients in this study, presented within $24 \mathrm{~h}$ of whiplash injury (WAD grade 2) to an emergency department. They were randomized to two therapy groups; 2-days vs. 10-days of immobilization with a soft cervical collar, $24 \mathrm{~h}$ a day. After 7 days, all patients started a standardized physical therapy program, 2-3 times a week for up to 6 weeks. Pain (assessed by VAS), disability (by VAS), and ROM were measured within $24 \mathrm{~h}$ of injury, and at 2 and 6 months. At both 2 and 6 months, there was no statistically significant difference between the groups for all measured outcomes (pain, disability, or ROM). The authors concluded that for patients with WAD grade 2 whiplash injury there is no difference between 2 and 10 days of immobilization with a soft cervical collar.

Therefore, there does not seem to be any significant benefit to extending the duration of collar usage. However, for those patients with acute neck pain, who prefer the use of a collar, it may be helpful, and at least for the first 10 days, it has not been found to be harmful.

\section{Radicular neck pain}

Cervical radiculopathy is a pathologic process involving the nerve root, arising from disk herniation, spondylosis, tumor, or trauma causing nerve root avulsion. Cervical radiculopathy may also occur in a setting in which no definite cause can be determined. The typical clinical picture is pain, paresthesia, weakness, or a combination of these symptoms [32]. In most studies, the pain is present in the upper limb more frequently than in the neck, although it is usually present in both the areas [33]. Cervical radiculopathy can usually be treated without surgery [34]. Although most studies discussing cervical collars for the management of pain have focused on whiplash patients, there have been a few that have studied patients with radicular pain.

Saal et al. [25] investigated 26 patients with cervical herniated nucleus pulposus and radiculopathy, most of whom presented with neurologic loss and were treated nonsurgically. All patients were treated with ice, rest, a hard cervical collar worn for up to 2 weeks, NSAIDs, traction, and strengthening exercises. Additionally, a physical rehabilitation program of 3 months duration was given to all patients, including instruction on body mechanics, adaptation of ADL's and proper cervical spine mechanics. More aggressive interventions were used (i.e. oral steroids, epidural injections) if there was no improvement with conservative measures. The patients were followed for a 1-year period. Data analyzed included symptom level, activity and function level, medication and ongoing medical care, job status, and satisfaction. After 1 year, 24 of the 26 patients were successfully treated without surgery and 20 of the 24 patients $(83 \%)$ had good or excellent outcomes. None of the patients had progressive neurological loss, and all patients with motor loss reached neurologic improvement. The authors concluded that many cervical disk herniations, which are commonly referred for surgery, can be successfully managed with aggressive nonsurgical treatment.

In this study, there were no control or comparison groups. Therefore, no conclusion can be made about the efficacy of surgery versus nonsurgical interventions. Additionally, we cannot conclude which specific nonsurgical interventions should be implemented. Therefore, although this study may suggest that a rigid cervical collar plays a role in treating cervical radiculopathy, there remains no clear evidence for or against the use of cervical collars.

Persson et al. [35], studied 81 patients with cervicobrachial pain of 3 months duration, in whom the distribution of the arm pain corresponded to the nerve root that was significantly compressed. The patients were randomly allocated to surgery, individually adapted physiotherapy, or a rigid cervical collar. The therapeutic effects were evaluated with respect to pain intensity by the Visual Analog Scale, function by the Sickness Impact Profile, and mood by Mood Adjective Check List. After 12 months, there was no difference in Visual Analog Scale, Sickness Impact Profile, or Mood Adjective Check List measurements among the groups.

Based on the above studies, no clear conclusion can be drawn as to the role of hard cervical collars for radicular pain. At best, these studies suggest that collars may be helpful when combined with other non-operative interventions.

\section{Cervical collars for spine stabilization}

Most trauma patients in the US arrive at the hospital immobilized [36]. Routinely, this immobilization includes a hard spine board, a cervical collar, and a means to prevent rotation of the head. A hard cervical collar and a firm mattress are the standard means of immobilizing patients with documented unstable injuries in the ED or ICU before application of traction or definitive stabilization. The multicenter National Emergency X-Radiography Utilization Study (NEXUS) enrolled 34,069 patients and determined which trauma patients require radiological clearance of the cervical spine [37]. They determined that only patients with midline neck tenderness, focal neurologic deficits, altered mental status, intoxication, or a 
painful distracting injury require radiographs to exclude spinal injury. These criteria were $99.6 \%$ sensitive for clinically significant injuries. Therefore, if the patient is neurologically intact, alert, without neck tenderness, they can be cleared from the precautions clinically, without obtaining a radiograph.

Cervical collars have been found to be helpful in the management of spinal stabilization for atlantoaxial rotatory subluxation (AARS) and various cervical spine fractures. A study by Subach et al. [38] reviewed the management of 20 children (mean age 6.4 years) with AARS. All the patients had presented with torticollis and symptoms of neck pain and decreased cervical motion for a mean of 11.2 days before diagnosis. Five patients were initially treated with a rigid cervical collar and anti-inflamatory agents. A total of 15 patients were treated with cervical traction. All the patients were immobilized post-reduction for approximately 12 weeks. Four of the five patients in the collar group reduced spontaneously, whereas the fifth required cervical traction and eventual fusion for recurrence. Of the 16 patients treated with traction, normal atlantoaxial alignment was restored in 15 . We see from this study that rigid cervical collars may play a role successfully managing AARS.

Kontautas et al. [39] concluded that nondisplaced axis fractures could be immobilized with a rigid cervical collar alone. Additionally, in a retrospective review of cervical spine injuries, the authors concluded that generally, vertical C2 body fractures are amenable to nonoperative treatment [40]. The $\mathrm{C} 2$ fractures in the study were immobilized with either a Minerva jacket, halo, or a rigid cervical collar. However, given the retrospective nature of the study and small sample size, recommendations regarding a specific device for external mobilization, cannot be made with certainty.

\section{Conclusion}

In whiplash patients, most studies suggest that early mobilization and activity is superior to immobilization and soft cervical collar use. However, more recent studies have not found any long-term benefits of early aggressive treatment as compared to immobilization. Therefore, no definite conclusion can be drawn about the efficacy of cervical collars in this population. Our conclusions are that cervical collars should not be universally recommended to all whiplash patients. However, for patients who find it useful for symptom relief, a soft cervical collar for 10 days or less has not been shown to have any adverse impact.

Rigid cervical collars have a well-established role in the acute management of trauma patients to prevent instability of the cervical spine. They also may play a role in the conservative treatment of certain types of cervical fractures such as nondisplaced axis fractures and $\mathrm{C} 2$ body fractures. However, since most of the studies done in patients with fractures, were case series and lacked an adequate control group, no specific recommendations can be made in this population.

Several studies suggest that hard cervical collars may play a role in the conservative management of cervical radiculopathy. However, sufficient evidence is lacking to advocate its routine usage. Further studies are needed for patients with non-traumatic axial neck pain, and radicular pain with or without trauma to understand the role that cervical collars may play in their management.

\section{References}

1. Cherry DK, Burt CW, Woodwell DA. National Ambulatory Medical Care Survey: 1999 summary. Adv Data Vital Health Stat 2001;322.

2. Bovim G, Schrader H, Sand T. Neck pain in the general population. Spine 1994;19:1307-9.

3. Westerling D, Jonsson BG. Pain from the neck-shoulder region and sick leave. Scand J Soc Med 1980;8:131-6.

4. Jackson R. Cervical trauma: not just another pain in the neck. Geriatrics 1982;37:123.

5. Bovim G, Schrader H, Sand T. Neck pain in the general population. Spine 1994;19:1307-9.

6. Gore DR, Sepic SB, Gardner GM, Murray P. Neck pain: a longterm follow up of 205 patients. Spine 1987;12:1-5.

7. Radanov B, Begre S, Sturzenegger M, et al. Course of psychological variables in whiplash injury. A 2 year follow-up considering features of injury mechanism and somatic, radiologic, and psychological findings. Medicine 1995;74:281-97.

8. Johnson RM, Hart DL, Simmons EF, et al. Cervical orthoses: a study comparing their effectiveness in restricting cervical motion in normal subjects. J Bone Joint Surg Am 1977;59:332.

9. Lysell E. Motion in the cervical spine, thesis. Acta Orthop Scand Suppl 1969;123:1-61.

10. Maiman D, Millington P, Novak S, et al. The effects of the thermoplastic Minerva body jacket on cervical spine motion. Neurosurgery 1989;25:363-8.

11. Braddom RL. Physical medicine and rehabilitation. 3rd ed. Saunders, 2006 [chapter 18, p. 361].

12. Naylor JR, Mulley GP. Surgical collars: a survey of their prescription and use. Br J Rheumatol 1991;30:282-4.

13. Huston GJ. Everyday aids and appliances. Collars and corsets. $\mathrm{Br}$ Med J 1988;296:276.

14. Spitzer WO, Skovron ML, Salmi LR, et al. Scientific monograph of the Quebec Task Force on whiplash associated disorders: redefining whiplash and its management. Spine 1995;20(8S):8S$58 \mathrm{~S}$.

15. Jarvinen MJ, Lehto MU. The effects of early mobilization and immobilization on the healing process following muscle injuries. Sports Med 1993;15:78-9.

16. Dehner C, Hartwig E, Strobel P, Scheich M, Scneider F, Elbel M, Kinzl L, Kramer M. Comparison of the relative benefits of 2 versus 10 days of soft cervical collar immobilization after acute whiplash injury. Arch Phys Med Rehabil 2006;87:1423-7.

17. Chan D, Goldberg R, Tascone A, et al. The effect of spinal immoblization on healthy volunteers. Ann Emerg Med 1994;23:48-51. 
18. Malcolm GP. Surgical disorders of the cervical spine: presentation and management of common disorders. J Neurol Neurosurg Psychiatry 2002;73 Suppl 1:i34-41.

19. Logan AJ, Holt MD. Management of whiplash injuries presenting to accident and emergency departments in Wales. Emerg Med J 2003;20:354-5.

20. Mealy K, Brennan H, Fenelon GC. Early mobilization of acute whiplash injuries. Br Med J 1986;292:656.

21. McKinney LA. Early mobilisation and outcome in acute sprains of the neck. Br Med J 1989;299:1006-8.

22. Rosenfeld M, Gunnarsson R, Borenstein P. Early intervention in whiplash associated disorders: a comparison of two treatment protocols. Spine 2000;25:1782.

23. Borchgrevnick GE, Kaasa A, McDonagh D, Stiles TC, Haraldseth O, Leriem I. Acute treatment of whiplash neck sprain injuries. A randomized trial of treatment during the first 14 days after a car accident. Spine 1998;23:25-31.

24. Schnabel M, Ferrari R, Vassiliou T, Kaluza G. Randomised controlled outcome study of active mobilization compared with collar therapy for whiplash injury. Emerg Med J 2004;21:306-10.

25. Verhagen AP, Scholten-Peeters GG, van Wijngaarden S, de Bie RA, Bierma-Zeinstra SM. Conservative treatments for whiplash. Cochrane Database Syst Rev 2007.

26. Logan AJ, Holt MD. Management of whiplash injuries presenting to accident and emergency departments in Wales. Emerg Med J 2003;20:354-5.

27. Kongsted A, Qerama E, Kasch H, Bendix T, Bach FW, Korsholm L, Jensen TS. Neck collar, "Act as Usual", or active mobilization for whiplash injury? Spine 2007;32(6):618-26.

28. Cote P, Hogg-Johnson S, Cassidy JD, Carroll L, Frank JW, Bombardier C. Early aggressive care and delayed recovery from whiplash: isolated finding or reproducible result? Arthritis Rheum 2007; 57(5):861-8.

29. Cassidy JD, Carroll LJ, Cote P, Frank J. Does multidisciplinary rehabilitation benefit whiplash recovery? Spine 2007;32(1):126-31.
30. Gennis P, Miller L Gallagher EJ. The effect of soft cervical collars on persistent neck pain in patients with whiplash injury. Acad Emerg Med 1996;3:568.

31. Dehner C, Hartwig E, Strobel P, Scheich M, Schneider F, Elbel M, Kinzl L, Kramer M. Comparison of the relative benefits of 2 versus 10 days of soft cervical collar immobilization after acute whiplash injury. Arch Phys Med Rehabil 2006;87:1423-7.

32. Ellenberg MR, Honet JC, Treanor WJ. Cervical radiculopathy. Arch Phys Med Rehabil 1994;75:342-52.

33. Honet JC, Puri K. Cervical radiculitis: treatment and results in 82 patients. Arch Phys Med Rehabil 1976;57:12-6.

34. Saal JS, Saal JA, Yurth EF. Nonoperative management of herniated cervical intervertebral disc with radiculopathy. Spine 1996;21:1877-83.

35. Persson LC, Carlsson CA, Carlsson JY. Long lasting cervical radicular pain managed with surgery, physiotherapy, or a cervical collar: a prospective randomized study. Spine 1997;22(7):751-8.

36. Hauswald M, Braude D. Spinal immobilization in trauma patients: is it really necessary? Curr Opin Crit Care 2002;8:56670.

37. Hoffman JR, Mower WR, Wolfson AB, et al. Validity of a set of clinical criteria to rule out injury to the cervical spine in patients with blunt trauma: national emergency x-radiography utilization study group. N Engl J Med 2000;343:94-9.

38. Subach BR, Mclaughlin MR, Albright AL, Pollack IF. Current management of pediatric atlantoaxial rotatory subluxation. Congress of Neurological Surgeons 1998;43(3):676-7.

39. Kontautas E, Ambrozaitis KV, Kalesinkas RJ, Spakauskas B. Management of acute traumatic atlas fractures. J Spinal Disord Tech 2005;18:402-5.

40. German JW, Hart BL, Benzel EC. Nonoperative management of vertical C2 body fractures. Neurosurgery 2005;56:516-21. 